OXIDATION OF ACETONE WITH POTASSIUM PERMANGANATE. 2657

Tribromophenol.-Calc. for $\mathrm{C}_{6} \mathrm{H}_{3} \mathrm{OBr}_{3} . \mathrm{KOH}: \quad \mathrm{K}$, IO. II \%; $\mathrm{H}_{2} \mathrm{O}, 4.67 \%$. Found: $\quad \mathrm{K}$, 10. $82 \%$; loss, $6.70 \%$.

o-Nitrophenol.-Clusters and moss-like masses of light yellow and red needles. When heated the mixture became uniformly deep red.

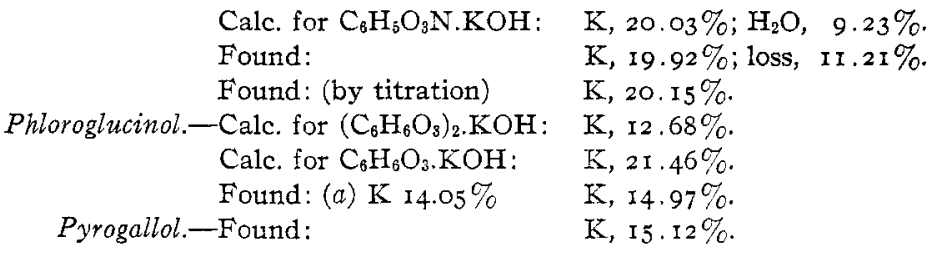

Miscellaneous Percentages of Potassium.-Gállic acid, 24.08. Stearic acid, 20. IO. Itaconic acid, 22.39. Salicylic acid, 21.33. Cyanuric acid, 30.I3. Vanilline, 28.8I. Guaiacol, 14.60. Aniline, 47.19. Acetanilide, 23.58. Citral, 4I.45. Phorone, 40.I6. Glycerol, a liquid, I5.58. Phenol, a liquid, 7.72. Resorcinol, 20.03. Catechol, I9.85. Amyl ether, 45.76. Anisol, 34.20. Veratrol, 26.32. Bornyl valerate, 40.47. Amyl formate, 4I.50. Acetal, 43.40. Acetyl bromide, 29. ro. Iodoform, 22.18. Ureas, 14.04. Carbon bisulfide very slowly formed beautiful, hygroscopic, bichromiate-colored crystals of $34.81 \% \mathrm{~K}$. Phenolphthalein formed a deep red mass. These and other additive compounds with other alkalies will be investigated.

A few oxygen-containing compounds, such as raffinose, saccharine, camphor, etc., failed to show any reaction with potash.

Seattle, Wash.

[CONtribution from the Otho S. A. Sprague Memorial Institute, Laboratory of Cinnical Research, Rush Medical College.]

\title{
THE ROLE OF ATMOSPHERIC OXYGEN AND ALKALI IN THE OXIDATION OF ACETONE WITH POTASSIUM PER- MANGANATE. PYRUVIC ACID AS AN IN- TERMEDIATE PRODUCT.
}

By Edgar J. WitzemanN.

Received September 4, 1917.

Since our knowledge of the nature of the chemical equilibria active in oxidations is quite limited it is highly desirable that more work be done to extend this knowledge. The following paper deals with the oxidation of acetone with potassium permanganate in the presence of varying amounts of alkali at room temperature. The purpose of these experiments was fourfold:

(I) To study the relative participation of atmospheric oxygen in the oxidation of acetone.

(2) To study the relative yields of acetic, oxalic and carbonic acids and to note, if possible, the reasons for the variations. 
(3) To form a general explanation of the mechanism of the oxidation of acetone in alkaline solutions.

(4) To get first-hand accurate knowledge concerning the relative ease of oxidation of acetone and glucose.

In some previous experiments on the oxidation of glucose ${ }^{1}$ with potassium permanganate it was noticed, when the initial concentration of alkali was varied, that among other things the amount of participation of atmospheric oxygen in the oxidation varied. Since it was well known that glucose in alkaline solution is oxidized by air and since it was likewise known that manganese oxide $(\mathrm{MnO})$ is sensitive to air oxidation especially in the presence of alkali there were three possible explanations for the participation of atmospheric oxygen in this oxidation.

(I) The atmospheric oxygen in the presence of alkali acts directly upon the glucose.

(2) The atmospheric oxygen in the presence of alkali acts upon the manganous oxide to form manganese dioxide, which, in turn, is reduced again by the glucose.

(3) The simultaneous action of (I) and (2).

In order to learn to what extent (2) might be significant it was desirable to oxidize some compound less sensitive than glucose to atmospheric oxidation in order to see if the same phenomenon occurred. Acetone is a compound that is well adapted to this purpose. In some experiments to be described it was shown that acetone is not acted upon by atmospheric oxygen even in the presence of alkati. In fact acetone is difficultly oxidized even by potassium permanganate as is indicated by the fact that the organic chemist has long been accustomed to use acetone as the solvent in the permanganate oxidation of organic compounds not sufficiently soluble in water, ${ }^{2}$ because it is so little acted upon by the permanganate. The results show that the above considerations do not rule out the large participation of atmospheric oxygen in these oxidations.

The second reason for doing these experiments was to learn more about the oxidation of acetone with permanganate. It was especially desired to know more about the effect of changing conditions on the nature of the products of oxidation. Hercz, ${ }^{3}$ in studying the behavior of various ketones with respect to Popoff's rule, found that acetone oxidized with two atoms of oxygen as potassium permanganate ${ }^{4}$ for each molecule of acetone gave only acetic, carbonic and traces of formic acids. G. Wagner ${ }^{5}$ alleged that the course of such oxidations was independent of the nature

1 This Journat, 38 , 150 (1916).

${ }^{2}$ Sachs, Ber., 34, 497 (19or).

${ }^{3}$ Ann., 186, 257 (1877).

4 [Cochenhausen showed later (J. prakt. Chem., 58, 45I (I898)) that more than two atoms of oxygen are required.]

- Ber., 25, Ref. I2 I. 
of the oxidizing agent. Cochenhausen, ${ }^{1}$ by using the potassium permanganate is variable but up to excessive proportions in very strongly alkaline solutions, found from $78.76 \%$ to $85.39 \%$ of the calculated amount of oxalic acid when using from 2.5 to 20 atoms of oxygen per molecule of acetone when the results were calculated according to the reaction

$$
{ }_{3} \mathrm{CH}_{3} \mathrm{COCH}_{3}+2 \mathrm{IO} \longrightarrow{ }_{3}\left(\mathrm{CO}_{2} \mathrm{H}\right)_{2} \cdot 2 \mathrm{H}_{2} \mathrm{O}+{ }_{3} \mathrm{CO}_{2} \text {. }
$$

The alternate reaction

$$
{ }_{3} \mathrm{CH}_{3} \mathrm{COCH}_{3}+\mathrm{I}_{4} \mathrm{O} \longrightarrow{ }_{2}\left(\mathrm{CO}_{2} \mathrm{H}\right)_{2} \cdot 2 \mathrm{H}_{2} \mathrm{O}+{ }_{2} \mathrm{CH}_{3} \mathrm{CO}_{2} \mathrm{H}+{ }_{2} \mathrm{CO}_{2}
$$

is, according to Cochenhausen, only of significance when quite insufficient permanganate is used, but accounts for the acetic acid found in those cases. In no case did Cochenhausen study the effect on the relative yield of acetic and oxalic acids, of varying the alkali concentration in his oxidation. Since he did not determine how much acetic acid was formed, these data cannot be obtained from his results. He states that he used Io g. potassium hydroxide in each experiment and that he diluted the reaction mixture to $200 \mathrm{cc}$. before analyzing but does not state what the concentration was at the time when the acetone was added.

Denis $^{2}$ studied the action of potassium permanganate on acetone in the course of more general study of the mechanism of oxidation. She performed three oxidations of acetone and found that acetic acid is formed as well as carbonic and oxalic acids and that the relative amount of oxalic acid increases with the concentration of potassium hydroxide used. These data are, however, not sufficient for our purposes.

The third reason for these experiments was to get some additional data for the oxidation of acetone in alkaline solutions. The existing amount of careful quantitative work on the oxidation of aliphatic compounds is still altogether too small to permit of accurate and definite applications of the results to the biological oxidation of fats and sugars.

The fourth reason for these experiments was of the greatest interest to the author. In a previous paper ${ }^{3}$ the oxidation of glucose with potassium permanganate in the presence of variable concentrations of alkali was studied with great care. It was now of interest to study the conduct of acetone under the same conditions. In certain diseases, and in fasting and starvation, it is generally thought there is a tendency for the fats to undergo the so-called $\beta$-oxidation, in part at least. The end members of this process are in part acetoacetic acid and acetone into which it spontaneously decomposes. When glucose (starch or sugar) is adequately metabolized by these individuals the excretion of these so-called "acetone bodies" ceases. It has never been adequately shown whether the glu-

1 J. prakt. Chem., 58, 45 I (I898).

${ }^{2}$ Am. Chem. J., 38, 572 (I9O7).

${ }^{3}$ Loc. cit. 
cose facilitates the oxidation of these compounds, as maintained by some or whether it prevents their formation. The author is of the latter opinion. These experiments offer some basis for this opinion and make a quantitative study of the oxidation of glucose and acetone within the same solution possible.

\section{Experimental Part.}

All the oxidations were carried out by dissolving $2 \mathrm{~g}$. of pure acetone in I000 cc. of water containing variable amounts of potassium hydroxide as shown in the tables. Two series of experiments were carried out owing to the fact that certain irregularities occurred in the first series. The two series amplify and confirm each other. The details of procedure were the same as in the oxidation of glucose. ${ }^{1}$ Small amounts of powdered permanganate were added to each flask and the mixture agitated from time to time until reduction was complete. When reduction no longer took place even after standing for several days the oxidation was considered complete. In Expt. 3, in Series II, reduction must not have been as complete as was thought when the oxidation was stopped. Details about the transformations of colloidal manganese dioxide in the first stages of the oxidation of acetone in this way have previously been published. ${ }^{2}$

The analytical methods were the same as those previously described. ${ }^{3}$ No method for determining the small amount of acetic acid was found that was entirely satisfactory. In some instances it was determined in the presence of hydrochloric acid;4 sometimes by the phosphoric acid method by distilling in vacuo or at ordinary pressure. Distillation with phosphoric acid in vacuo was in general most satisfactory.

\section{Discussion of the Results.}

Potassium Permanganate.-As stated in the introductory part one purpose of this work was to continue the observations on the relative participation of atmospheric oxygen in oxidations in alkaline solutions with potassium permanganate. In the first place it was necessary to know whether acetone is oxidized by atmospheric oxygen. In order to determine this $\mathrm{r} g$. acetone was made up to $500 \mathrm{cc}$. with enough alkali to make the concentrations as follows: (I) no alkali; (2) o. or $N$ potassium hydroxide; (3) $0.05 \mathrm{~N}$; (4) $0.010 \mathrm{~N}$; (5) $0.20 \mathrm{~N}$. $5 \mathrm{cc}$. of the mixture were titrated at once for acetone by the Lieben iodoform method. 1.04 g. was the average acetone content. The flasks were stoppered tightly with rubber stoppers and were agitated vigorously at least once each day. After 12 days at room temperature the average acetone content was

${ }^{1}$ Loc. cit.

2 This Journal, 39, 28 (1917).

${ }^{3}$ Loc. cit., p. I52.

4 Evans and Witzemann, This JournaL, 34, IO86 (Igr2). 
I.03 g. After I month the average acetone content was found to be $\mathrm{r} .03 \mathrm{~g}$. These experiments show that acetone is not oxidized by atmospheric oxygen.

For details concerning the interpretation of the permanganate deficiency see the earlier paper. ${ }^{1}$ It is sufficient to say here that a comparison of the values in Cols. II and III in the tables shows that here too there is a deficit in the amount of permanganate actually utilized as compared with that calculated from the products of the reaction. In this case the deficit is more regular throughout the series and in neither series does it reach such high values as with glucose. The irregular values are in part due to the irregularities in the analysis of the products of the oxidation (especially acetic acid) from which these deficits were derived by calculation.

In general, we may conclude that since atmospheric oxygen does not act upon acetone in alkaline solutions up to $0.20 \mathrm{~N}$ concentrations, that if atmospheric oxygen does directly oxidize acetone according to the first suggested explanation, it does so at some stage lower in the oxidation than acetone itself.

In the second series of oxidations which were carried out more quickly the permanganate deficits were smaller in the less alkaline solutions than in the first series.

Products of the Oxidation.--In both series oxidation in the first experiment was imperceptibly slow. On standing a month or more the first small portion of permanganate (0. I-o.2 g.) added was partially reduced. ${ }^{2}$

In Expts. 2 and. 3 in both series the oxidation was more rapid but came to equilibrium before all the acetone was reduced, as is shown by the figures in Col. XVII. The oxidation in Expt. 3, in Series II, was probably incomplete. In the second series the unchanged acetone was determined in 13 experiments and the results showed that in the remaining experiments oxidation was complete.

The general results showed that it is possible to obtain every degree of velocity of oxidation from zero to almost instantaneous reaction in the oxidation of acetone with potassium permanganate by suitable variations in the alkalinity. It is thus clear that in these experiments the alkalinity alone determines the velocity of oxidation.

Cochenhausen ${ }^{3}$ concluded from his study of this reaction that in the presence of alkali and sufficient permanganate the main reaction is

${ }^{1}$ Loc. cit., pp. $155^{-8}$.

2 It has long been known that acetone is resistant to oxidation by even such a powerful oxidizing agent as potassium permanganate. Thus Péan de Saint-Gilles (Compt. rend., 47, 554 (1858)); Ann. chim. phys., [3] 55, 374 (1858)) as well as Sachs ( $\mathrm{Ber}, 34,497$ (1901)) knew that permanganate is dissolved unchanged in acetone. In fact permanganate has been used to remove methyl alcohol from commercial acetone (Friedel, Ann. chim. phys., [4] I6, 405 (I869); Martine, Ibid., [8] 3, 82 (1904)).

Loc. cit. 
(I) ${ }_{3} \mathrm{CH}_{3} \mathrm{COCH}_{3}+{ }_{2} \mathrm{IO} \rightarrow{ }_{3}\left(\mathrm{CO}_{2} \mathrm{H}\right)_{2} \cdot 2 \mathrm{H}_{2} \mathrm{O}+{ }_{3} \mathrm{CO}_{2}$ and that

(2) $3 \mathrm{CH}_{3} \mathrm{COCH}_{3}+\mathrm{r}_{4} \mathrm{O} \longrightarrow{ }_{2}\left(\mathrm{CO}_{2} \mathrm{H}\right)_{2} \cdot 2 \mathrm{H}_{2} \mathrm{O}+{ }_{2} \mathrm{CH}_{3} \mathrm{CO}_{2} \mathrm{H}+{ }_{2} \mathrm{CO}_{2}$ is only of significance when inadequate amounts of permanganate are used. The latter reaction was designed to explain the formation of acetic acid and in doing so apparently assumes that some sort of a condensation takes place since otherwise three molecules of carbon dioxide and one or two molecules of acetic or oxalic acid would have been formed. The results of my experiments show that Reaction 2 is not true at least for the conditions used in these experiments.

The tabulated results and the earlier work cited throughout this paper indicate clearly that in the formation of the final products there are at least two courses of reaction:

(I) $\mathrm{CH}_{3} \mathrm{COCH}_{3}+4 \mathrm{O} \longrightarrow \mathrm{CH}_{3} \mathrm{CO}_{2} \mathrm{H}+\mathrm{CO}_{2}+\mathrm{H}_{2} \mathrm{O}$

(2) $\mathrm{CH}_{3} \mathrm{COCH}_{3}+7 \mathrm{O} \longrightarrow\left(\mathrm{CO}_{2} \mathrm{H}\right)_{2}+\mathrm{CO}_{2}+\mathrm{H}_{2} \mathrm{O}$,

occurring simultaneously and the extent to which the one or the other preponderates depends on the velocity of that reaction under the conditions of the experiment. Of these the second is identical with Cochenhausen's first reaction. The results show that the first reaction becomes less significant as the alkalinity increases so that in Expt. I6 the oxidation takes place about $65 \%$ according to Reaction 2 and only about $35 \%$ according to $\mathrm{I}$. The results also show that very little, if any, acetone is oxidized solely to carbon dioxide thus:

$$
\mathrm{CH}_{3} \mathrm{COCH}_{3}+{ }_{4} \mathrm{O}_{2} \longrightarrow{ }_{3} \mathrm{CO}_{2}+{ }_{3} \mathrm{H}_{2} \mathrm{O}
$$

Much of the discussion of the products of oxidation in the paper on glucose oxidation ${ }^{1}$ is of interest in this connection, but will not be repeated here. One of the most interesting facts brought out in that discussion was the fact that an additional $0.8 \mathrm{~g}$. of potassium hydroxide in one experiment as compared with the preceding caused an increase of $10.6 \%$ in the yield of oxalic acid. Calculations showed that this sharp change in the nature of the products was due to the fact that when the available alkali becomes equal to the amount required for normal salts of the products the yield of oxalic acid becomes maximum (see the graph). Owing to the fact that oxalic acid in alkaline solutions is not freely oxidized, the results indicated that one important role of the alkali was to stabilize the oxalic acid which is also an intermediate in the oxidation of glucose even in the absence of alkali. ${ }^{2}$

In the case of the acetone oxidations the available alkali (Col. XXI) exceeds that required for the formation of normal salts in Expts. 3 to r6, but there is no such break in the yield of oxalic acid as was observed in

${ }^{1}$ Loc. cit., pp. 158-6o.

2 Smolka, Sitzb. Math. nat. Klasse k. Akad. Wiss., Wien, 2, 5-30 (1887). 
the oxidation of glucose. In fact the yield in oxalic acid rises gradually and continually from the first to the last experiment (see the graph). This would indicate that there is an intermediate rearrangement or transformation upon which the formation of oxalic acid is dependent. When this transformation does not take place the intermediate compound in

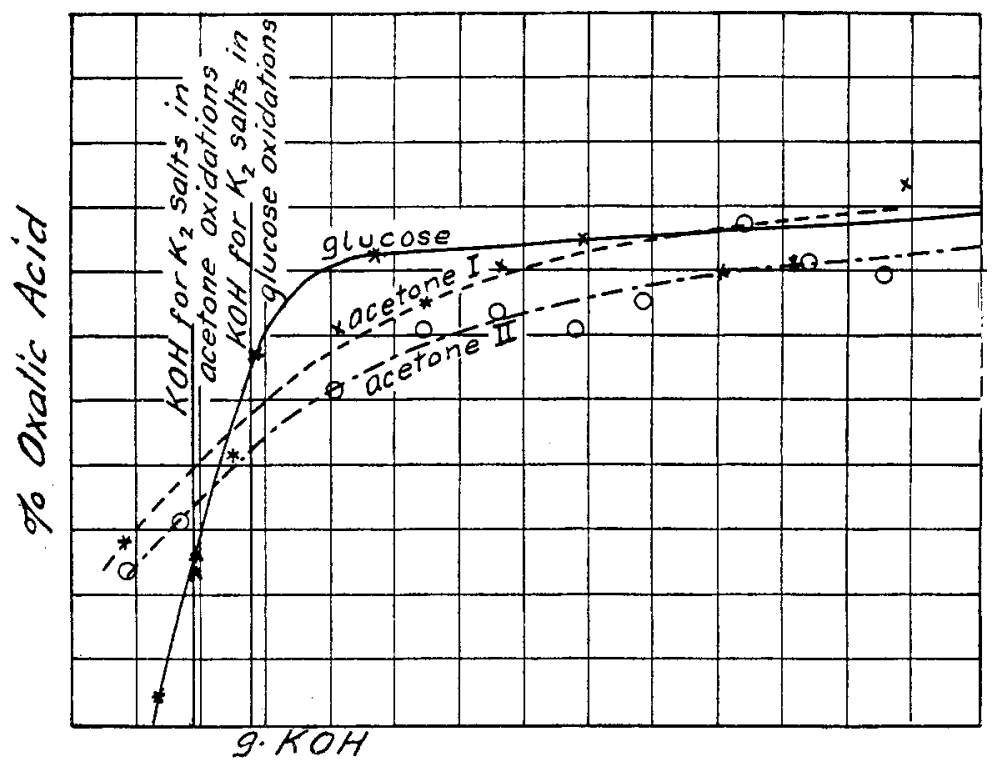

question is oxidized to acetic and carbonic acids instead of oxalic and carbonic acids. The extent to which this transformation takes place is indicated by the ratio of the two groups of products since both are stable toward permanganate under the conditions of the experiment.

Such an intermediate change could be the enolization of pyruvic acid, $\mathrm{CH}_{3} . \mathrm{CO} . \mathrm{COOH}$ into $\mathrm{CH}_{2}$ : $\mathrm{COH} . \mathrm{COOH}$, discussed below.

\section{The Mechanism of the Oxidation.}

In the earlier experiments on the oxidation of glucose under analogous conditions very little could be said about the mechanism of the oxidation from the point of view of the glucose. It seems much more likely that the mechanism of the oxidation of acetone can be more fully interpreted owing to the relative simplicity of its constitution. Dr. Denis ${ }^{1}$ has in fact already discussed the mechanism of this process rather fully on the basis of Nef's conceptions and came to the conclusion that the formation of oxalic acid from acetone is due to the successive intermediate formation of acetol, pyruvic and mesoxalic acids. The acetol, in her opinion, is obviously obtained from the oxidation of isoacetone molecules, which are present in an alkaline solution of acetone. Her argument for this conception is summarized in the following quotation:

${ }^{1}$ Am. Chem. J., 38, 561 (1907). 
"An aqueous solution of acetone contains the following molecules in dynamic equilibrium:

$$
\mathrm{CH}_{3} \mathrm{COCH}_{3} \rightleftarrows \mathrm{CH}_{3} \mathrm{COH}+\lesseqgtr \mathrm{CH}_{2}
$$

"When therefore, this ketone is oxidized in neutral or acid solution with an excess of permanganate, bichromate, etc., acetic and carbonic acids are formed in exactly molecular amounts. An aqueous solution of acetone can consequently contain no trace of enol or $\beta$-hydroxypropylene molecules. As soon however, as a certain definite and very small amount of potassium hydroxide is added to the solution the presence of isoacetone molecules can at once be rigidly established by experimentation in three different ways:

"( (I) By the quantitative transformation into mercuric- $\beta$-hydroxypropylene.

“(2) By conversion of acetone into diacetone alcohol, $\left(\mathrm{CH}_{3}\right)_{2}: \mathrm{COH} \cdot \mathrm{CO} \cdot \mathrm{CH}_{3}$ (addition of the $\beta$-hydroxypropylene molecules, with anionic rearrangement, to unchanged acetone).

"(3) By the almost quantitative oxidation of the $\beta$-hydroxypropylene molecules with intermediate formation of acetol, trihydroxypropene, $\mathrm{CH}_{3} \mathrm{C}(\mathrm{OH})_{2} \mathrm{CHOH}$, into equimolecular quantities of carbonic and oxalic acids.

"Acetone, as has long been known, does not react in aqueous solution with freshly precipitated and well washed mercuric oxide. As soon, however as an alkali is added a practically quantitative conversion into white mercuric isoacetone, $\left(\mathrm{CH}_{8} . \mathrm{CO}\right)_{2} \mathrm{Hg}$,

takes place with marked evolution of heat.

"This shows very clearly ( $I$ ) that an aqueous solution of acetone contains no $\beta$-hydroxypropylene molecules; and (2) that such molecules appear in the solution of addition of small amounts of potassium or sodium hydroxide and that their presence can at once be recognized in the three ways indicated above."

Before fully accepting the above interpretation of the behavior of acetone it is desirable to see whether it is in harmony with other observations. The only other oxidation of acetone that is quantitatively carried out in an alkaline medium is the titration of acetone as iodoform by the Lieben method. The most adequate existing explanation of this oxidation is that of Pieroni and Tonnioli ${ }^{1}$ and involves a conception fundamentally similar to that of Denis.

Pieroni and Tonnioli found in a study of the mechanism of the formation of iodoform from acetone and acetaldehyde ${ }^{2}$ that the formation of iodoform is due to the action of hypoiodite and the quantity of iodoform produced depends on the quantity of hypoiodite that reacts. In order to explain the fact that $93.4 \%$ of the iodine consumed is combined in iodoform instead of $50 \%$ as required by an older theory, on the assumption that half of the iodine is lost as hydriodic acid Pieroni and Tonnioli formulated an explanation based on the fact that ethylene adds hypochlorous acid to form glycolhydrin

$$
\mathrm{CH}_{2}: \mathrm{CH}_{2}+\mathrm{HClO} \longrightarrow \mathrm{CH}_{2} \mathrm{OH} \cdot \mathrm{CH}_{2} \mathrm{Cl} \text {. }
$$

${ }^{1}$ Gazz. chim. ital., 43, II, 620 (1913).

2Ibid., 42, I, 534 (1912). 
They represent their explanation graphically as follows:

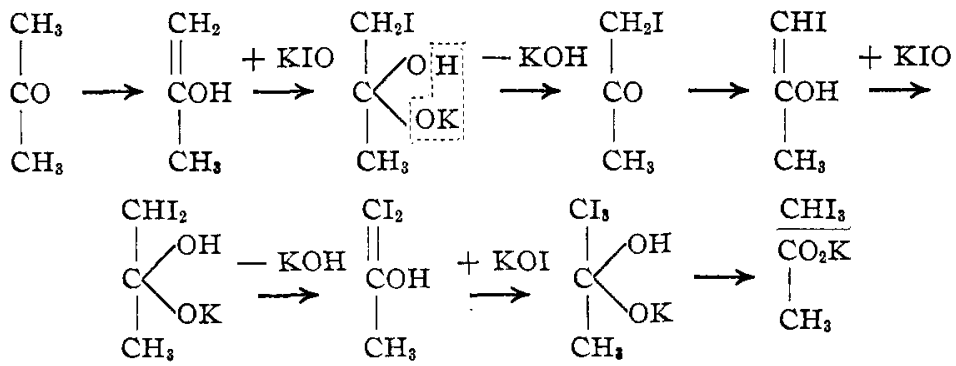

Since the reaction as far as the iodine is concerned is $93 \%$ quantitative it follows that the deviations from the reaction, according to which one molecule of acetone gives one molecule of iodoform and one of acetic acid, cannot be great. So that although there is room for side reactions, they must be of relatively small importance. If we accept Denis' first suggestion about the dissociation of acetone thus:

$$
\mathrm{CH}_{3} \mathrm{COCH}_{3} \rightleftarrows \mathrm{CH}_{3} \mathrm{COH}+\mathrm{CH}_{2},
$$

we should expect the acetaldehyde to react with hypoiodous acid to give iodoform finally ${ }^{1}$ and likewise the methylene residue should react. This would result in the utilization of more iodine by this acetone molecule than is provided for on the basis of the above reaction scheme. Thus it is possible that the discrepancy of $7 \%$ may be accounted for by just such a side reaction as that provided for by the above-mentioned dissociation equilibrium.

Thus by assuming that dissociations of the above type exist in acetone solutions as well as the isoacetone equilibrium (enol form) it becomes possible to understand both types of reactions in the same medium by remembering that the velocity constants for the two types must be quite different.

About a year after the appearance of Denis' paper Fournier ${ }^{2}$ studied the oxidation of acetone with potassium permanganate in the presence of sodium, potassium, calcium and barium hydroxides as well as sodium and potassium carbonates with special reference to the intermediate formation of pyruvic acid. The pyruvic acid was isolated as the phenylhydrazone and although the reaction was very sensitive to slight changes in conditions, the maximum yield was $9 \%$ pyruvic acid as the phenylhydrazone. Glückmann had previously ${ }^{3}$ obtained a similar result.

Denis' interpretation of the oxidation of acetone depended on indirect evidence and although apparently not known to Fournier, was confirmed,

'Pieroni, Gazz. chim. ital., 42, I, 534 (I9I2).

2 Bull. soc. chim., [4] 3, 256 (Igo8).

'Monatsh., 10, 782 (1889). 
by him so far as the intermediate formation of pyruvic acid is concerned. ${ }^{1}$

The general significance of these results must be that pyruvic acid is a relatively stable intermediate oxidation product of those three-carbon compounds that are capable of giving rise to it. The list of such compounds if all of the rather unstable intermediates like acetol, methyl glyoxal, lactic aldehyde, etc., are included is quite a long one.

On the basis of the above general discussion, it is now possible to construct a scheme for the oxidation of acetone analogous to that of Pieroni and Tonnioli for the formation of iodoform, thus:

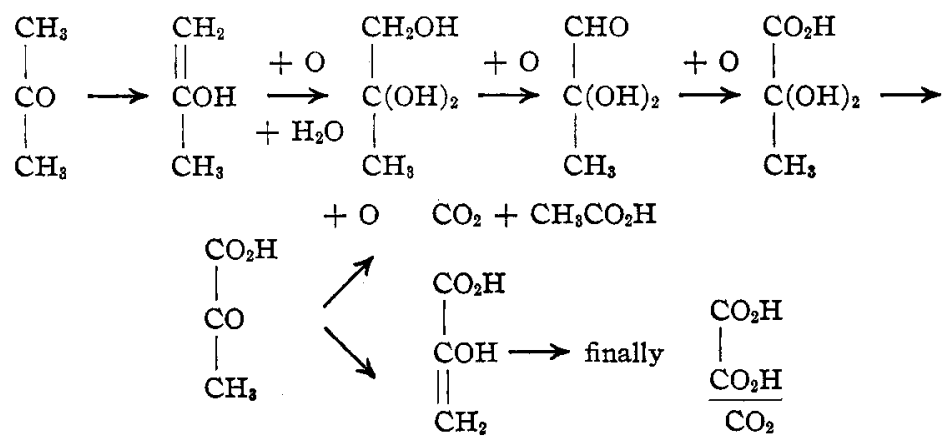

This scheme:

(I) readily permits of the explanation of the simultaneous formation of acetic and oxalic acids in the oxidation of acetone;

(2) is in agreement with Denis' conclusions about the properties of acetone in alkaline solutions;

(3) is supported by Fournier's experiments ${ }^{2}$ on the formation of pyruvic acid;

(4) is in line with Pieroni and Tonnioli's explanation of the formation of iodoform;

(5) is supported by my own conclusions about the significance of the relative rate of increase in the yield of oxalic acid.

In the above experiments the observations of earlier workers that acetone is not acted upon by potassium permanganate in the absence of alkali was confirmed. The quotation from Denis' paper establishes the fact that it is the isoacetone $\mathrm{CH}_{2}: \mathrm{COH} . \mathrm{CH}_{3}$ in alkaline solutions that is reactive, and that the permanganate in the absence of extra alkali is incapable of producing a sufficient amount by hydrolysis to promote

1 [It is of importance in this connection to note that Beilstein and Weigand (Ber., I7, 840 ( 1884$)$ ) found pyruvic acid as an intermediate in the oxidation of calcium lactate with permanganate. Moreover the author in some earlier experiments (Dissertation, Ohio State Univ., I9I2) on the oxidation of propylene glycol with permanganate concluded that pyruvic acid was an intermediate product although unaware at the time of Fournier's experiments on acetone.]

${ }^{2}$ Loc. cit. 
rapid oxidation. If this interpretation is acceptable the only point in the above scheme that is open to objection, that has not been discussed, is the question as to whether pyruvic acid may enolize in the way indicated. At this point the question may fairly be asked: If the methyl group in acetone can only be attacked after enolization why should that in pyruvic acid be attacked without? Such effects of the ketone group on the adjoining part of the molecule are very general and are discussed by Meyer and Jacobson. ${ }^{1}$ Moreover, this effect appears to occur especially strongly in pyruvic acid, ${ }^{2}$ as is indicated by the numerous spontaneous condensation reactions to which it is subject, ${ }^{3}$ and for which such an enolization constitutes a simple explanation. With enolized pyruvic acid as with other enolized molecules, the velocity of reaction is enormously increased by the presence of alkali. Thus Wolff ${ }^{4}$ found that the condensation of pyruvic acid is greatly accelerated by the presence of potassium or barium hydroxide, potassium cyanide or ammonia. ${ }^{5}$

Nothing can be said with certainty about other intermediate stages than the above. In fact it is not certain but what the enolization of the second methyl group takes place before pyruvic acid is reached as for instance with acetol, but more likely with methyl glyoxal. But at whatever stage it does take place or in whatever intermediate condition the compounds may exist (such for instance as the dissociation forms so much used by Nef) it seems clear that the second methyl group is not involved in that portion giving rise to acetic and carbonic acids.

The possible importance of $\alpha$-keto acids in biology cannot be estimated at present because so little is known about them. Aside from pyruvic acid (which is easily obtained and has been rather much studied) the only

${ }^{1}$ Lehrbuch der Organischen Chemie, II, 670 (1907).

2 [Denis stated (Loc. cit., p. 576) that "enol molecules of pyruvic acid must of necessity be present in the alkaline solution."]

" [Meyer and Jacobson, "Lehrbuch der Organischen Chemie," III, III8 (19I3); cf. Finck, $A$ nn., I22, I82 (1862); Böttinger, Ber., 6, 895 (I873); 8, I583 (1875); 9, 836 (1876); I8,609(1885); Ann., I72, 239 (1874); I88, 300 (1877); 208, 122 (I88I); Mulder, Rec. trav. chim., 12, 86 (I893); 13, 393 (1894); I4, 297 (1895); de Jong, Ibid., 20, 81, 365 (I901); 2I, I9I, 299 (I902); 25, 229 (I906); Gault, Compt. rend., I53, IO9 (I9II); but especially I. Wolff, $A n n ., 305$, I25, I54 (1899); 317, I, 22 (I901).]

${ }^{4}$ Loc. cit.

5 [The earlier experiments on the oxidation of propylene glycol, lactic and pyruvic acids (Evans and Witzemann, Loc. cit.) are susceptible to the same interpretation as far as the formation of oxalic acid is concerned. That is pyruvic acid, which as was stated above occurs as an intermediate is enolized by the alkali and it is the oxidation of this enol that determines how much oxalic acid is formed. The experiments of Evans and Day (THIs JouRNaI, 38, 375 (1916)) on the oxidation of ethyl alcohol with permanganate in the presence of variable amounts of alkali, with the sole production of acetic, oxalic and carbonic acids are susceptible to a similar interpretation on the basis that the intermediate product acetaldehyde is enolized to give vinyl alcohol (McLeod, Am. Chem. J., 37, 24 (1907).] 


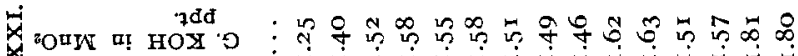

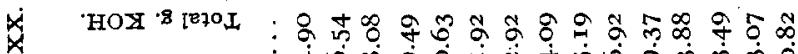

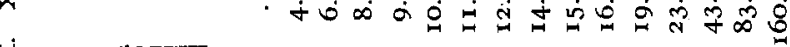

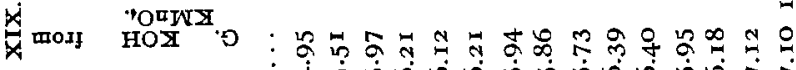

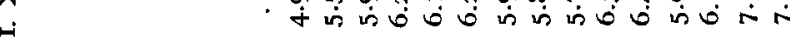

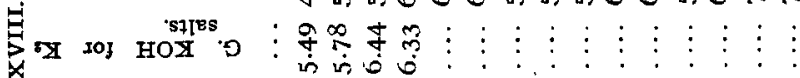

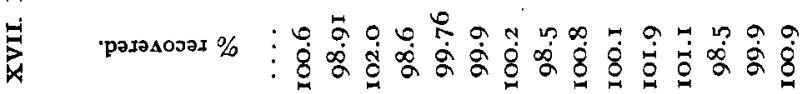
-

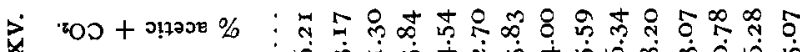

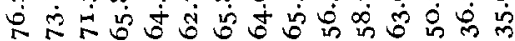

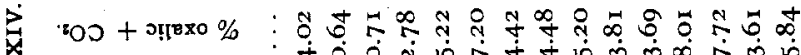

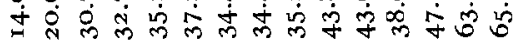

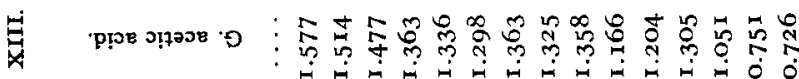

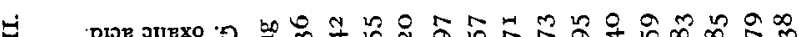

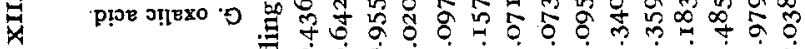

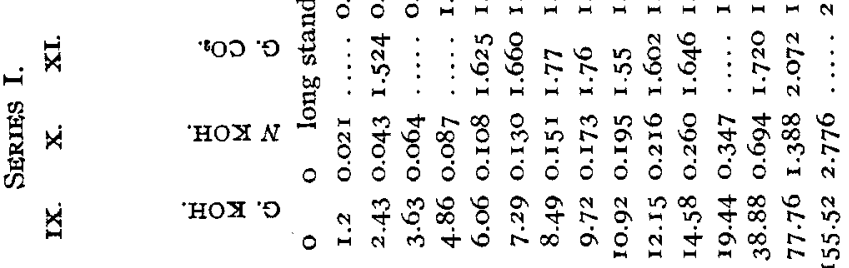

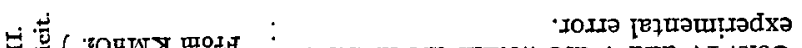

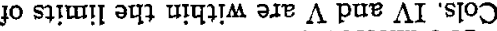

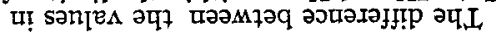

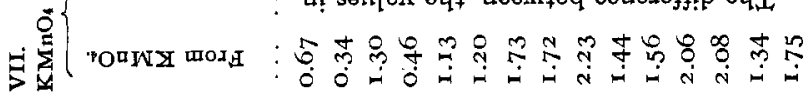

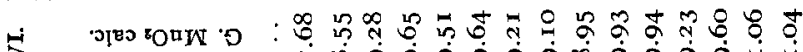

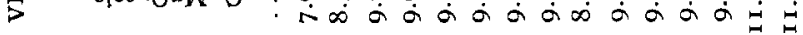

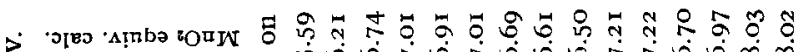
$\rightarrow \quad$ AInba

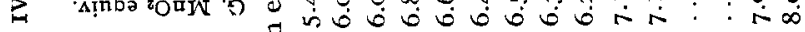

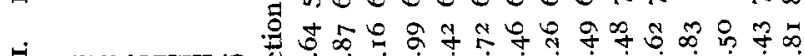

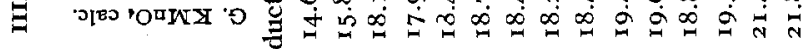
H.

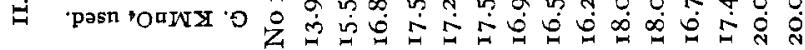
h. 


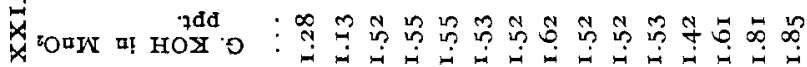

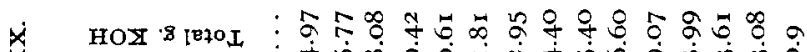

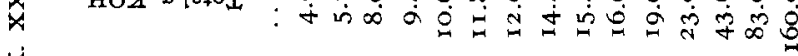

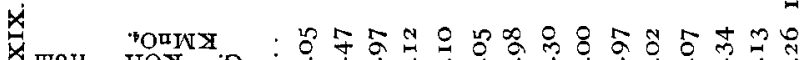

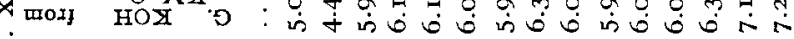

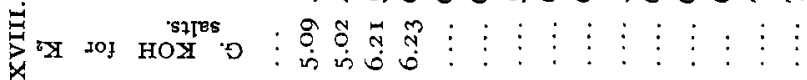

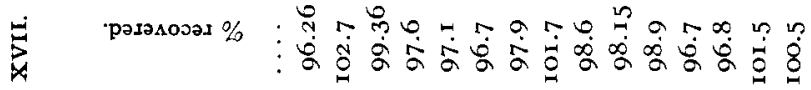

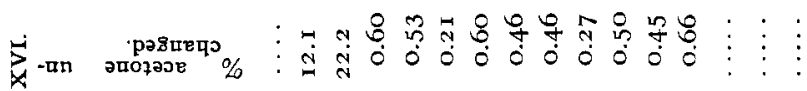

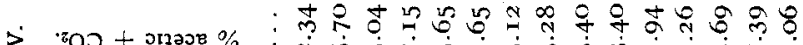

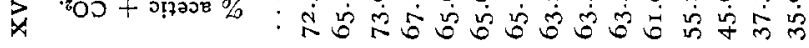
翁 雨

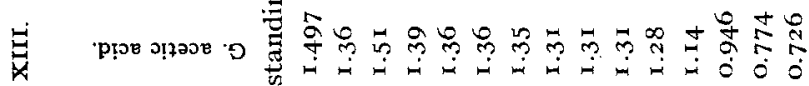

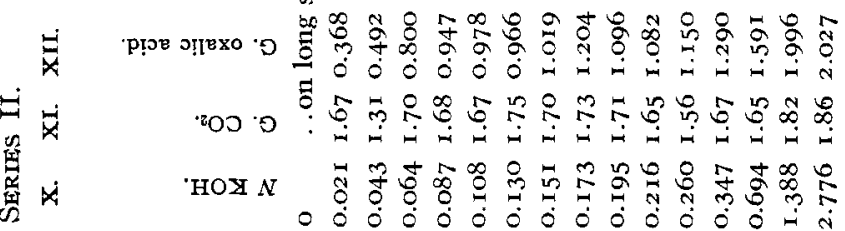
× Hox 0 \% ๆ मा ले

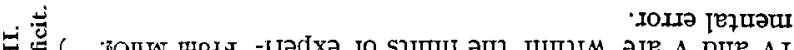

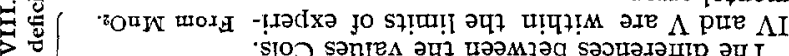

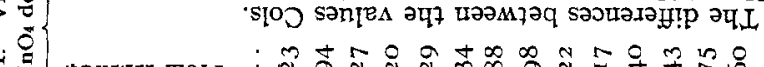

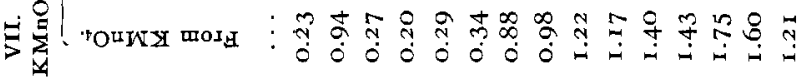

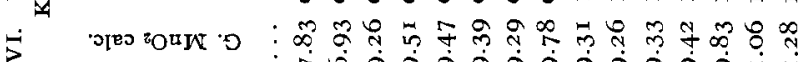
तो

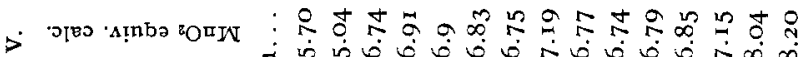

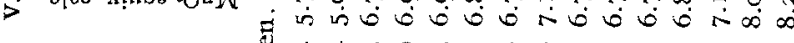

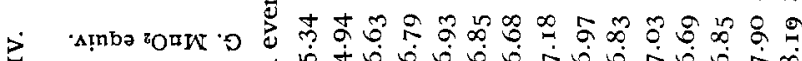

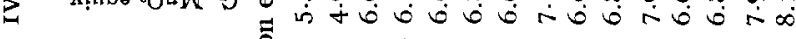

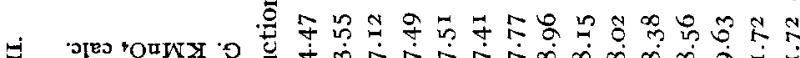
$\exists$ गण

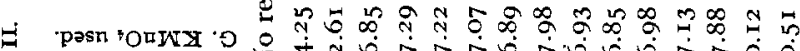

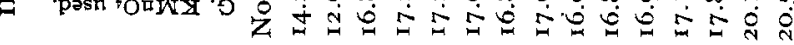

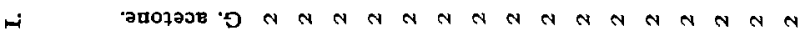
- 
one well known is glyoxylic acid. C. Neuberg's discussion of the sugar exchange of the cell ${ }^{1}$ indicates the possible great importance of pyruvic acid in sugar metabolism in plants and animals. The possible importance of the homologs of pyruvic acid in fat metabolism has apparently never received serious consideration, although a moment's thought will convince one that they are capable of tremendous importance in this connection. The author hopes to deal with this suggestion in greater detail elsewhere.

\section{Résumé.}

Experiments were made on the oxidation of acetone with potassium permanganate in the presence of variable amounts of alkali in order to see whether the oxidation of this substance, which is not perceptibly oxidized by air even in the presence of alkali, nor by permanganate except in the presence of alkali, is also accompanied by spontaneous oxidation resulting in the utilization of less than the calculated amount of permanganate. It was found that the deficit in the permanganate consumed that was observed in the oxidation of glucose ${ }^{2}$ also occurs here. In the earlier paper it was concluded that this deficit can be explained in one of three ways: (I) a large part of the manganese dioxide is reduced to a manganous compound and subsequently oxidized to manganese dioxide by the air; (2) the alkali serves as a catalyst in facilitating the oxidation of the organic compound; (3) the combined effect of (I) and (2). From the above experiments we may conclude that ( $I$ ) is true unless the atmospheric oxygen acts upon some lower stage in the oxidation of acetone.

In the absence of alkali acetone is not perceptibly oxidized by permanganate at room temperature. In the presence of small amounts of alkali the oxidation is incomplete-unchanged acetone remains at the end of the oxidation. In the presence of sufficient alkali the acetone is oxidized solely to acetic, oxalic and carbonic acids in such a way that one molecule of carbonic acid is formed for each molecule of acetic and oxalic acids. The proportion of oxalic acid increases gradually but continually with increasing alkalinity. This is different from what was observed for glucose where the maximum yield of oxalic acid was obtained as soon as the available alkali exceeds that required for the formation of normal salts of the acid products, and is interpreted as signifying that the formation of oxalic acid depends on a molecular transformation that is catalyzed or dependent on alkali. Such a transformation would be the conversion of pyruvic acid into its enol isomer, $\mathrm{CH}_{2}: \mathrm{COH} . \mathrm{COOH}$. It was shown by the previous results of other workers on the oxidation and chemical properties of acetone and by the general characteristics of ketone deriva-

${ }^{1}$ C. Oppenheimer, Hdb. d. Biochem. d. Menschen u. Tiere, Erganzungsb., I9r3, pp. $569-6 \mathrm{II}$.

${ }^{2}$ Loc. cit. 
tives that such a transformation would tend to occur. On the basis of all the evidence presented there cannot be any doubt that the enolization of pyruvic acid represents a logical and simple explanation of the deviation of the oxidation products from mostly acetic and carbonic acids to mostly oxalic and carbonic acids.

From all the above discussion it is clear that alkali performs at least the following functions in the oxidation of acetone:

(I) It gives rise to the reactive enol-isoacetone;

(2) It brings about the enolization of pyruvic acid;

(3) It neutralizes the acids formed and thus interferes with their further oxidation;

(4) It alone determines the velocity of oxidation;

(5) It catalyzes the absorption of atmospheric oxygen.

The point of view developed in this paper concerning the mechanism of the oxidation of acetone is of great interest in the interpretation of the oxidative breakdown of fatty acids. This relation will be discussed in a subsequent paper.

CHICAGO, ILL.

[CONTRIBUTION FROM IHE FORFSt PRODUCTS I,ABORATORY, U. S. DEFT. OF AGRICULTURE.]

\section{THE ACTION OF ALUMINUM CHLORIDE ON CYMENE.}

By A. W. SCHORGER.

Received August 28, 1917.

The information available on the action of aluminum chloride on cymene is very meagre. Anschüt ${ }^{1}$ heated cymene with one-third of its weight of aluminum chloride and cursorily remarked that the liquid reaction product contained "betrachtliche Mengen von Toluol." The high boiling portions gave no fractions of uniform boiling point. Boedtke and Halse $^{2}$ heated $90 \mathrm{~g}$. of cymene and $900 \mathrm{~g}$. of benzene with aluminum chloride and obtained $44 \mathrm{~g}$. of toluene and $68 \mathrm{~g}$. of cumene. ${ }^{3}$ The following is a study of this reaction, with determinations of the amount of toluene obtained under different conditions and with the identification of several other components of the reaction.

\section{Experimental Part.}

Cymene.--The cymene used was obtained from "sulfite turpentine."4 The portion distilling between $175^{\circ}$ and $178^{\circ}$ was fractioned repeatedly

${ }^{1}$ Ann., 235, 191 (1886).

2 Bull. soc. chim., 19, 444 (1916).

- After the work on this paper was completed a brief reference to the action of aluminum chloride on cymene was made by Moore and Egloff (Met. Chem. Eng., 17, 66 (r917)). They obtained but $14.3 \%$ toluene with small amounts of benzene and xylene.

Turpentine recovered during the manuiacture of puip from resinous wood by the sulfite process. 